\title{
ARTICLE
}

\section{Truth: The Rule or the Aim of Assertion?}

\author{
Neri Marsili (6) \\ Alma Mater Studiorum, Università di Bologna, Italy \\ Email: nerimarsili@gmail.com
}

(Received 7 April 2021; revised 16 May 2021; accepted 23 June 2021)

\begin{abstract}
Is truth the rule or the aim of assertion? Philosophers disagree. After reviewing the available evidence, the hypothesis that truth is the aim of assertion is defended against recent attempts to prove that truth is rather a rule of assertion.
\end{abstract}

Keywords: Assertion; truth; linguistic normativity; speech act theory; language game

\section{Rules vs aims}

Is truth the rule or the aim of assertion? ${ }^{1}$ If truth is the rule of assertion, one should only assert what is true, so that every false assertion constitutes a violation of the rule that governs assertion. If truth is instead the aim of assertion, in making an assertion one only purports to be trying ${ }^{2}$ to say something true: false assertions are therefore sub-optimal, since they fail to meet their purported aim, but they are not ipso facto in violation of a linguistic or epistemic norm.

Each view has prominent defenders. The former of these two hypotheses is supported by proponents of the "Truth Rule" of assertion, according to which one should only assert what is true (Weiner 2005; Whiting 2012, 2015; MacFarlane 2014; cf. also Alston 2000), and by proponents of the "Knowledge Rule" of assertion, according to which one should assert only what one knows. ${ }^{3}$ The rival thesis that truth is the aim of assertion (rather than its rule) is perhaps less popular; it has been defended by Dummett (1973), Williams (2002), and Marsili (2018). Let us call 'factive accounts' the family of views that takes truth to be a rule of assertion (including the

\footnotetext{
${ }^{1}$ We could of course envisage a third possibility: that truth is neither the aim nor the rule of assertion. I will come back to this third option and why it is unsatisfying in section 2, as I discuss 'non-factive views' about the norm of assertion.

${ }^{2}$ The expression "purports to be trying" may sound redundant, but 'trying' alone would not do here. Not all agents who engage in an aim-based activity actually try to meet the aim of that activity; but all purport (in a sense) to be trying to meet it. So, for instance, not all chess players actually try to checkmate their opponents, but (prima facie) they all purport to be trying to checkmate their opponents. Similarly, if truth is the aim of assertion, it does not follow that all assertors actually try to tell the truth, only that assertors are (prima facie) purporting to be trying to tell the truth. What exactly is meant by 'purporting' clearly needs unpacking; for elaboration, the interested reader may refer to Marsili (2018).

${ }^{3}$ Since knowledge entails truth, also the Knowledge Rule entails that truth is a rule, rather than the aim, of assertion (Williamson 1996, 2000).

(C) The Author(s), 2021. Published by Cambridge University Press. This is an Open Access article, distributed under the terms of the Creative Commons Attribution licence (http://creativecommons.org/licenses/by/4.0/), which permits unrestricted re-use, distribution, and reproduction in any medium, provided the original work is properly cited.
} 
Knowledge Rule), and 'truth-aim accounts' the family of views that takes truth to be the aim of assertion.

So far, these two families of views have coexisted peacefully: proponents of factive accounts have not been interested in proving that truth-aim views were incorrect, nor vice versa. In a recent article, however, I have offered an argument that attempts to establish that truth is the aim, rather than the rule, of assertion (Marsili 2018). Turri (2020) has since objected that arguments for truth-aim accounts are ineffective, and that factive accounts are in a better position to explain assertion's relation with truth.

This paper assesses the positive case in favour of truth-aim accounts, and argues that Turri's objections fail to undermine existing support for truth-aim views. Although the debate is far from being settled, we currently have solid reasons to think that truth is the aim, rather than the rule, of assertion.

\section{Turri's argument against the truth-aim view}

In Marsili (2018), I introduced a "puzzle about assertion and truth" that aimed to show that truth-aim accounts are better suited to explain our linguistic behaviour and our intuitions about assertability. The puzzle emerges from the apparent tension between two sets of observations that seem intuitively correct:

IMPROPER FALSITY:

Intuition: false assertions are improper in virtue of their being false.

Behaviour: false assertions are reproachable in virtue of their being false.

PERMISSIBLE FALSITY:

Intuition: inadvertently false ('unlucky') assertions are permissible.

Behaviour: we do not reproach unlucky assertors. ${ }^{4}$

At first blush, factive accounts are in a good position to explain IMPROPER FALSITY (since they hold that false assertions are impermissible) but seem incompatible with PERMISSIBLE FALSITY (since they maintain that all false assertions violate a norm). By contrast, any account that posits a non-factive rule for assertion (i.e. any account according to which assertion is subject to a rule that does not require truth, such as the Belief Rule or the Justification Rule ${ }^{5}$ ) will be consistent with PERMISSIBLE FALSITY, but will alone lack the resources to explain what is wrong about false assertions (IMPROPER FALSITY).

Conveniently, the truth-aim account can accommodate both sets of data, faring better than both competitors. Unlike factive accounts, the truth-aim account is compatible with PERMISSIBLE FALSITY: if truth is the aim rather than the rule of assertion, false assertions are incorrect, but not impermissible. But (unlike non-factive views) the truth-aim hypothesis can also explain IMPROPER FALSITY: if truth is the aim of assertion, false assertions miss the target, and as such are defective and criticisable. ${ }^{6}$

\footnotetext{
${ }^{4}$ Marsili (2018: 640).

${ }^{5}$ The view that assertion is governed by a Belief-Rule is defended by Hindriks (2007) and Bach (2008). The view that assertion is governed by a Justification-Rule has several defenders, but the first scholars to discuss it in the recent literature were Douven (2006), Lackey (2007), and Kvanvig (2009). For a more detailed overview of non-factive norms, see Pagin (2014).

${ }^{6}$ Here I am merely reconstructing the argument I presented in Marsili (2018); the reader can refer to the original article for a more detailed discussion of each point.
} 
So far, only Turri (2020) has challenged this argument for truth-aim accounts. Turri's attack relies on three main argumentative steps. First, Turri argues that (A) IMPROPER FALSITY and PERMISSIBLE FALSITY "are not actually inconsistent", so that "there is no puzzle to resolve", and no positive case for the truth-aim account can be derived from them (Turri 2020: 475). Second, he argues that (B) factive accounts are actually able to explain both sets of data. This leads him to the conclusion that $(\mathrm{C})$ once we consider all the evidence available, factive accounts fare much better than truth-aim views: truth is the rule, rather than the aim, of assertion. Let us consider each argumentative step in turn.

\section{Missing the mark}

It is not hard to show that Turri's objection (A) misses the mark, in that it does not really undermine the positive case for truth-aim accounts of assertion. To see why, let us break it down into three simpler claims: (A) here indicates the alleged flaw in the argument, and $\left(\mathrm{A}^{\prime}\right)-\left(\mathrm{A}^{\prime \prime}\right)$ what we can infer from it.

(A) The two sets of linguistic data are not actually inconsistent.

(A') Therefore, there is no puzzle to resolve.

(A") Therefore, the argument for truth-aim accounts fails.

The first observation (A) is surely correct, but it is not actually in tension with the argument for truth-aim accounts. Quite the contrary: we must accept (A) for the argument to work: since the truth-aim account is meant to solve the puzzle by accommodating both sets of data (PERMISSIBLE FALSITY and IMPROPER FALSITY), the pair cannot be inconsistent. In fact, I myself accept (A), since in Marsili (2018) I argued that, on the truth-aim account, a false assertion can both be improper (qua failure to meet the aim) and permissible (since it is not by definition in violation of a norm, as factive accounts would have it $)^{7}$.

Once this is clear, we can reject both (A') and (A"). We can reject (A') (that "there is no puzzle to resolve") because a puzzle to resolve still remains: even if IMPERMISSIBLE FALSITY and IMPROPER FALSITY are not inconsistent, we still need to find an account that is able to accommodate both, and it is not obvious that a rule-based account (be it factive or not) can do it. This is the puzzle that the truth-aim account purports to solve. ${ }^{8}$ We can also reject (A") (that "The argument for the truth-aim account fails"). Since at no point the argument for the truth-aim account relies on the assumption that the two sets of linguistic data are inconsistent, this conclusion is unwarranted. Turri's response misses the mark: it concentrates all its energies on demonstrating that $(A)$ is true, on the mistaken assumption that it will help establish (A").

It is worth noting that there is a further reason why Turri's objection fails: there is a second argument that purports to support the idea that truth is the aim (rather than the

\footnotetext{
${ }^{7}$ One can see that this claim is perfectly coherent with Turri's alleged refutation: "from the fact that a behavior is improper, it does not follow that it is impermissible. Some permissible behavior is nevertheless improper" (Turri 2020: 476).

${ }^{8}$ In all fairness, this is not the puzzle that Turri has in mind, since Turri is assuming that we would have a puzzle only if the two sets of data were inconsistent. But why we should make this further assumption is unclear. What we need to establish is whether there is a reading of the 'puzzle' that supports the truth-aim account; not if there is an uncharitable reading that doesn't. In different terms: while (A') may be true on one reading of the word 'puzzle', so interpreted (A') would also be too weak to play its intended role namely, supporting an inference to (A").
} 
rule) of assertion, and that is left untouched by Turri's critique. To fully appreciate what we would need to successfully undermine the existing case in favour of truth-aim accounts, let us consider it briefly. The claim is that if one accepts the following test, one has a reason to think that truth is the aim, rather than the rule, of assertion:

\section{TEST FOR THE RULE/AIM DISTINCTION:}

For any given action $\mathrm{A}$ within a practice $\mathrm{P}$, for any given condition $\mathrm{C}$ applying to $A$, for any competent and careful agent $S$, the truth of $(T)$ is prima facie evidence that $\mathrm{C}$ is the aim of $\mathrm{A}$ in $\mathrm{P}$, whereas the falsity of $(\mathrm{T})$ is prima facie evidence that $\mathrm{C}$ is the rule of $\mathrm{A}$ in $\mathrm{P}$ :

(T) S can typically try but fail to meet $\mathrm{C}$

Why should we accept the test? Simplifying, the idea is that rules are typically 'fair', in the (very) minimal sense that typically they do not punish good-willing agents who do their best to follow them. ${ }^{9}$ Aims, by contrast, do not tend to be designed so as to ensure that the good-willing agents who intend to achieve them will achieve them. Quite the opposite: aims are often elusive by design. A game that one cannot play without winning would not be a very interesting game, because the aim of winning would be too easy to achieve. If the TEST (or something in its ballpark) is valid, it would seem to provide evidence in favour of the truth-aim account. Since we often try but fail to assert the truth, $(\mathrm{T})$ is satisfied by assertions: the TEST supports the hypothesis that truth is the aim of assertion, rather than its rule.

Whether the TEST is valid may indeed be debated. But the point here is that in order to effectively undermine the positive case for truth-aim accounts, one would need to address the TEST. There is therefore a second respect in which Turri's attack to truth-aim accounts misses the mark: it concentrates all its efforts in establishing (A), when (A) is actually compatible with the truth-aim account, and turns instead a blind eye to the TEST, which provides independent evidence in favour of the view. In short, both the pillars that support truth-aim accounts are left unscathed by Turri's attack.

\section{Weighing the evidence}

Undermining the truth-aim view need not rely on undermining one or more positive arguments for it. An alternative, more general approach is to prove that factive accounts are preferable because they have (overall) more explanatory power than truth-aim views. The second half of Turri's paper takes this approach: it presents some reasons to prefer factive accounts to truth-aim accounts, namely points (B) and (C) mentioned earlier, which I report here:

(B) Factive accounts can explain both IMPERMISSIBLE FALSITY and PROPER FALSITY.

(C) Factive accounts explain the rest of the available data better than truth-aim accounts.

Whether (B) is true, and whether a genuinely factive account can accommodate both sets of data, is currently a matter of dispute, and several authors have argued against it (Douven 2006: 478-80; Lackey 2007; Stone 2007: 100; Engel 2008; Koethe 2009: 631; Cappelen 2011: 46; Gerken 2011; Greenough 2011: 208; Kvanvig 2011: 242;

\footnotetext{
${ }^{9}$ Let me stress that the claim here is not that most rules are fair in the ordinary sense of the word. The claim is much weaker: namely, that rules do not typically punish agents who do their best to follow them.
} 
Hinchman 2013; Schechter 2017). ${ }^{10}$ More importantly, even if we concede (B) for argument's sake, (B) does not yet speak in favour of factive accounts over truth-aim accounts: if both views can explain the data, the two accounts are on a par in this respect. ${ }^{11}$ Finally, since only the truth-aim passes the TEST FOR THE RULE/AIM DISTINCTION, the evidence would still weigh in favour of the truth-aim account. In short: even if (B) were true (which is forcefully disputed in the literature), it would still not help us establish, alone, that factive accounts are preferable to truth-aim accounts.

There are two further arguments in support of (C); let us consider them in turn. The first is that endorsing factive accounts "doesn't require us to accept ancillary hypotheses about the aim of assertion", which is an advantage because "every ancillary hypothesis or assumption with probability less than 1 automatically decreases the probability that one's view as a whole is correct"(Turri 2020: 477). But this would be for the pot to call the kettle black. Both factive accounts and truth-aims accounts make assumptions about a putative link between truth and assertion: the former account assumes that truth is the rule of assertion, the latter that truth is the aim of assertion. It is not clear whether we should classify these claims as 'ancillary assumptions' (rather than conclusions established with arguments); but even if we do, the fact remains that the assumptions are postulated in equal number by each view. ${ }^{12}$ Of course, we could dispute the grounds on which each assumption is introduced. But Turri's claim here is that factive accounts avoid ancillary assumptions and are by definition more likely to be true. This stronger claim is simply indefensible.

The second argument in support of (C) is that factive accounts cohere "with a wide and increasing range of additional evidence", whereas "Marsili's discussion proceeds by setting aside all of the [evidence against the truth-aim account]" (Turri 2020: 477-8). But while there is indeed evidence that supports factive accounts, an equally impressive case has been built against them (and, more specifically, against the Knowledge Rule and the Truth Rule). ${ }^{13}$ It is far from clear that a simple appeal to the literature is sufficient to establish that factive accounts enjoy some explanatory advantage in this sense.

Furthermore, it would seem that proponents of factive accounts would also have to "proceed by setting aside" some relevant evidence. The TEST FOR THE RULE/AIM DISTINCTION, which was designed exactly to settle the disagreement, is glaringly omitted from Turri's discussion. Lacking a refutation of the TEST, and established that there is no consensus in the literature on whether the norm of assertion is factive, ${ }^{14}(\mathrm{C})$ remains a difficult claim to defend.

It is therefore unclear that Turri (and, more generally, proponents of factive accounts) currently has a strong case for (C). To be sure, it could still be pointed out that, given the widespread disagreement about norms of assertion, it would be too

\footnotetext{
${ }^{10}$ For an empirical study that bears on whether (B) is true, see also Marsili and Wiegmann (2021: fn 14 and $\$ 5.2)$.

${ }^{11}$ This point is anticipated and discussed in Marsili (2018: 646).

${ }^{12}$ If something, it would seem that factive accounts are guilty of being committed to extra ancillary assumptions, such as the assumption that the rule governing assertion is constitutive of the speech act, which has been repeatedly challenged in the literature (e.g. Cappelen 2011; Pagin 2016; Marsili 2019).

${ }^{13}$ For theoretical arguments, see Douven (2006), Lackey (2007), Kvanvig (2009), McKinnon (2015), Pelling (2011, 2013); for empirical counterevidence, Kneer (2018), Reuter and Brössel (2019), Marsili and Wiegmann (2021).

${ }^{14}$ That assertion has a world-to-word direction of fit is instead a consensus view in speech act theory, and proponents of truth-aim accounts claim to be able to accommodate this point better than their factive rivals (Marsili 2018: 644-5). Where there is agreement, then, it would seem that it is rather factive views that will have trouble accommodating the consensus view.
} 
optimistic to think that the TEST (or any of the evidence brought up in favour of the truth-aim hypothesis) settles the debate in favour of truth-aim accounts. But this is not something that defenders of truth-aim accounts need to be committed to. They may take a weaker stance towards the available evidence and maintain, more modestly, that the truth-aim account stands in a privileged position to explain a diverse range of data, including IMPROPER FALSITY, PERMISSIBLE FALSITY, and the TEST FOR THE RULE/AIM DISTINCTION. So interpreted, the view that truth is the aim of assertion remains unchallenged by Turri's criticisms.

\section{Conclusions}

We have seen that the hypothesis that truth is the aim (rather than the rule) of assertion is supported by solid arguments, which are left unscathed by recent attempts to undermine them. This does not mean, however, that the debate is settled once and for all in favour of truth-aim accounts. More modestly, the contention is that truth-aim accounts are able to accommodate a wide range of linguistic data, including some that do not sit well with the rival view that assertion is subject to a factive norm. Because of this, the view that truth is the aim of assertion represents a promising and explanatorily powerful hypothesis, which rivals other prominent accounts in plausibility, including the popular Knowledge Rule of assertion. ${ }^{15}$

\section{References}

Alston W.P. (2000). Illocutionary Acts and Sentence Meaning. Ithaca, NY: Cornell University Press.

Bach K. (2008). 'Applying Pragmatics to Epistemology.' Philosophical Issues 18, 68-88.

Cappelen H. (2011). 'Against Assertion.' In J. Brown and H. Cappelen (eds), Assertion: New Philosophical Essays, pp. 21-48. Oxford: Oxford University Press.

Douven I. (2006). 'Assertion, Knowledge, and Rational Credibility.' Philosophical Review 115(4), 449-85.

Dummett M. (1973). Frege: Philosophy of Language. London: Duckworth.

Engel P. (2008). 'In What Sense Is Knowledge the Norm of Assertion?' Grazer Philosophische Studien 77 (1), 99-113.

Gerken M. (2011). Warrant and Action. Synthese 178(3), 529-47.

Greenough P. (2011). 'Truth-Relativism, Norm-Relativism, and Assertion.' In J. Brown and H. Cappelen (eds), Assertion: New Philosophical Essays, pp. 197-232. Oxford: Oxford University Press.

Hinchman E.S. (2013). 'Assertion, Sincerity, and Knowledge.' Nô̂s 47(4), 613-46.

Hindriks F. (2007). 'The Status of the Knowledge Account of Assertion.' Linguistics and Philosophy 30(3), 393-406.

Kneer M. (2018). 'The Norm of Assertion: Empirical Data.' Cognition 177, 165-71.

Koethe J. (2009). 'Knowledge and the Norms of Assertion.' Australasian Journal of Philosophy 87(4), 625-38.

Kvanvig J.L. (2009). 'Assertion, Knowledge, and Lotteries.' In D. Pritchard and P. Greenough (eds), Williamson on Knowledge, pp. 140-60. Oxford: Oxford University Press.

Kvanvig J.L. (2011). 'Norms of Assertion'. In J. Brown and H. Cappelen (eds), Assertion: New Philosophical Essays, pp. 233-51. Oxford: Oxford University Press.

Lackey J. (2007). 'Norms of Assertion.' Nô̂s 41(4), 594-626.

MacFarlane J. (2014). Assessment Sensitivity: Relative Truth and Its Applications. Oxford: Clarendon Press. Marsili N. (2018). 'Truth and Assertion: Rules versus Aims.' Analysis 78(4), 638-48.

Marsili N. (2019). 'The Norm of Assertion: A “Constitutive" Rule?' Inquiry. doi: 10.1080/ $0020174 x .2019 .1667868$.

Marsili N. and Wiegmann A. (2021). 'Should I Say That? An Experimental Investigation of the Norm of Assertion.' Cognition. doi: 10.31234/osf.io/cs45j.

McKinnon R. (2015). Norms of Assertion: Truth, Lies, and Warrant. London: Palgrave-Macmillan.

\footnotetext{
${ }^{15}$ The author would like to thank Michele Palmira and Giorgio Volpe for valuable comments on earlier versions of this draft.
} 
Pagin P. (2014). 'Assertion'. In E.N. Zalta (ed.), Stanford Encyclopedia of Philosophy. https://plato.stanford. edu/entries/assertion/.

Pagin P. (2016). 'Problems with Norms of Assertion.' Philosophy and Phenomenological Research 93(1), 178-207.

Pelling C. (2011). 'A Self-Referential Paradox for the Truth Account of Assertion'. Analysis 71(4), 688.

Pelling C. (2013). 'Paradox and the Knowledge Account of Assertion.' Erkenntnis 78(5), 977-8.

Reuter K. and Brössel P. (2019). 'No Knowledge Required.' Episteme 16(3), 303-21.

Schechter J. (2017). 'No Need for Excuses Against Knowledge-First Epistemology and the Knowledge Norm of Assertion.' In J.A. Carter, E.C. Gordon and B.W. Jarvis (eds), Knowledge First: Approaches in Epistemology and Mind, pp. 132-59. Oxford: Oxford University Press.

Stone J. (2007). 'Contextualism and Warranted Assertion.' Pacific Philosophical Quarterly 88, 92-113.

Turri J. (2020). 'A Non-Puzzle about Assertion and Truth.' Logos \& Episteme 4, 475-9.

Weiner M. (2005). 'Must We Know What We Say?' Philosophical Review 114(2), 227-51.

Whiting D. (2012). 'Stick to the Facts: On the Norms of Assertion.' Erkenntnis 78(4), 847-67.

Whiting D. (2015). 'Truth Is (Still) the Norm for Assertion: A Reply to Littlejohn.' Erkenntnis 80(6), 1245-53.

Williams B.A.O. (2002). Truth and Truthfulness An Essay in Genealogy. Princeton, NJ: Princeton University Press.

Williamson T. (1996). 'Knowing and Asserting'. Philosophical Review 105(4), 489-523.

Williamson T. (2000). Knowledge and Its Limits. Oxford: Oxford University Press.

Neri Marsili is a Research Fellow at the University of Bologna. His research concerns normative aspects of communication, with a particular emphasis on dishonest speech. His publications include "Assertion and truth: rules versus aims" (Analysis), "Should I say that? An empirical investigation of the norm of assertion" (Cognition, with A. Wiegmann), "Lying, speech acts, and commitment" (Synthese), and "Retweeting: its linguistic and epistemic value" (Synthese). Together with Peter Pagin, he manages the "Assertion" entry of the Stanford Encyclopedia of Philosophy.

Cite this article: Marsili N (2021). Truth: The Rule or the Aim of Assertion? Episteme 1-7. https://doi.org/ 10.1017/epi.2021.28 